\title{
Hypothesis and Theory: Revisiting Views on the Co-evolution of the Melanocortin Receptors and the Accessory Proteins, MRAP1 and MRAP2
}

\author{
Robert M. Dores* \\ Department of Biological Sciences, University of Denver, Denver, CO, USA
}

\section{OPEN ACCESS}

Edited by:

Nicole Gallo-Payet,

University of Sherbrooke, Canada

Reviewed by:

Stacia A. Sower,

University of New Hampshire, USA

Erica Crespi,

Washington State University, USA

Jose Miguel Cerda-Reverter,

Consejo Superior de Investigaciones

Cientificas, Spain

Patricia M. Hinkle,

University of Rochester Medical

Center, USA

Gert Flik,

Radboud University Nijmegen,

Netherlands

*Correspondence:

Robert M. Dores

rdores@du.edu

Specialty section: This article was submitted to Neuroendocrine Science, a section of the journal

Frontiers in Endocrinology

Received: 08 April 2016

Accepted: 17 June 2016

Published: 28 June 2016

Citation:

Dores RM (2016) Hypothesis and Theory: Revisiting Views on the

Co-evolution of the Melanocortin

Receptors and the Accessory

Proteins, MRAP1 and MRAP2.

Front. Endocrinol. 7:79.

doi: 10.3389/fendo.2016.00079
The evolution of the melanocortin receptors (MCRs) is closely associated with the evolution of the melanocortin-2 receptor accessory proteins (MRAPs). Recent annotation of the elephant shark genome project revealed the sequence of a putative MRAP1 ortholog. The presence of this sequence in the genome of a cartilaginous fish raises the possibility that the mrap1 and mrap2 genes in the genomes of gnathostome vertebrates were the result of the chordate $2 \mathrm{R}$ genome duplication event. The presence of a putative MRAP1 ortholog in a cartilaginous fish genome is perplexing. Recent studies on melanocortin-2 receptor (MC2R) in the genomes of the elephant shark and the Japanese stingray indicate that these MC2R orthologs can be functionally expressed in $\mathrm{CHO}$ cells without co-expression of an exogenous mrap1 cDNA. The novel ligand selectivity of these cartilaginous fish MC2R orthologs is discussed. Finally, the origin of the mc2r and $m c 5 r$ genes is reevaluated. The distinctive primary sequence conservation of MC2R and MC5R is discussed in light of the physiological roles of these two MCR paralogs.

Keywords: melanocortin receptors, MRAP1, MRAP2, MC2R, MC5R, evolution

\section{INTRODUCTION}

In many respects, the features of the melanocortin receptor (MCR) gene family (i.e., $m c 1 r, m c 2 r$, $m c 3 r, m c 4 r, m c 5 r)$ are rather straightforward. These G Protein-coupled receptors are only found in chordates (1), and the proliferation of paralogous genes in this family has been influenced by the two genome duplication events that occurred during the early evolution of the chordates (2-4). In addition, these receptors appear to be predominately coupled to a cAMP/PKA pathway at their respective target cells (5). Finally, all of the MCRs are activated by one or more of the melanocortin-related peptides (i.e., ACTH, $\alpha$-MSH, $\beta$-MSH, $\gamma$-MSH, or $\delta$-MSH), which are derived from the precursor protein, POMC in gnathostomes (6), and the precursors POM or POC in lampreys (7).

There are also features of this gene family that are somewhat unique. For example, some of the MCRs interact with the accessory proteins melanocortin- 2 receptor accessory protein (MRAP) 1 and MRAP2 $(8,9)$, and these interactions can affect receptor trafficking and activation. In addition, for teleosts and tetrapods, the MC2R paralog has exclusive ligand selectivity for ACTH as compared to the more permissive ligand selectivity of the other MCR paralogs for ACTH and the MSH-sized ligands (10). Finally, while it is assumed that two genome duplications should yield four paralogous genes, 
there are five paralogous genes present in this family. Hence, the origin of the fifth gene and the physiological significance of the fifth gene are another issue that will be revisited.

\section{PHYLOGENY AND PROPOSED EVOLUTION OF THE MRAPS}

Following the initial cloning of the five MCRs, pharmacology studies for each receptor were done in heterologous nonadrenal cortex-derived mammalian cell lines with one exception - MC2R (6). Mountjoy et al. (11) found that in order to examine the ligand selectivity of human MC2R, the receptor cDNA needed to be expressed in Cloudman S91 melanoma cells; a cell line that endogenously expresses the $M c 1 r$ gene. Subsequent studies would show that mammalian MC2R orthologs could be functionally expressed in cell lines derived from adrenal cortex cells, but not in non-adrenal mammalian cell lines (12-15). These observations contributed to the discovery of the accessory protein, MRAP (16).

Melanocortin-2 receptor accessory protein is a single chain polypeptide with one membrane-spanning domain. This transmembrane (TM) protein forms a homodimer at the endoplasmic reticulum in which the two monomers are oriented in an antiparallel manner [reverse topology; for reviews, see Ref. $(8,9)$ ]. In the human genome, there are two paralogous MRAP genes, MRAP or MRAP1 (16), and MRAP2 (17). For this discussion, "mrap" will be used to refer to the ancestral accessory protein gene, and mrap1 and mrap2 will be used to designate the two paralogous members of the gene family. As a reference for the discussion that will follow, Table 1 summarizes the observations from Chan et al. (17) with respect to the effects of human MRAP $1 \alpha$ and human MRAP2 on the activation and trafficking of the five human MCRs.

The salient features of the MRAPs are illustrated by mouse MRAP1 and MRAP2 (Figure 1). For MRAP1, the LKANKH motif is required for reverse topology (18), and the corresponding reverse topology motif in mouse MRAP2 is LKAHKY, [(8); Figure 1]. Reverse topology motifs are also apparent in the chicken and zebrafish MRAP1 and MRAP2 orthologs (Figure 1).
The TM domain of mouse Mrap1 is required for the trafficking of MC2R to the plasma membrane (18), and the corresponding sequence in mouse Mrap2 (Figure 1) has 43\% amino acid sequence identity with the TM domain of mouse Mrap1. Among the MRAP1 orthologs presented in Figure 1, the amino acid sequence identity between mouse Mrap1 and chicken MRAP1, and mouse Mrap1 and zebrafish MRAP1 is 74 and $48 \%$, respectively. This level of sequence identity is apparently adequate since both chicken MC2R (19) and zebrafish MC2R (20) can be activated when co-expressed in heterologous mammalian cells with their respective MRAP1 ortholog. It is interesting that the amino acid sequence identity for the TM region of the MRAP2 orthologs presented in Figure $\mathbf{1}$ is 74\%. Since MRAP2 is expressed in brain and adrenal cortex cells, there appears to be selection pressure to maintain the TM sequences of MRAP2 orthologs. The physiological roles of the MRAP2 orthologs will be discussed later in this section.

Given the preceding comments on primary sequence similarity, the most striking difference between mouse Mrap1 and Mrap2 is the activation motif present in Mrap1 that is conspicuously absent in Mrap2 (Figure 1). As a result, although MC2R will move to the plasma membrane in the presence of MRAP2, activation of the receptor following an ACTH-binding event is barely detectable at concentrations of ACTH of $10^{-8} \mathrm{M}$ or less $(8,9,21)$. Conversely, in the presence of MRAP1, the activation of MC2R is robust following an ACTH-binding event [(16); Table 1]. It would appear then, that when a mammalian MC2R ortholog is expressed alone, the receptor miss-folds, and is non-functional (22). When co-expressed with MRAP1, MC2R assumes an active conformation, and the MC2R/MRAP1 complex can be activated by ACTH. Interaction with an MRAP1 paralog to achieve functional expression is a strict requirement for teleost and tetrapod MC2R orthologs $(20,23)$.

Sebag and Hinkle (18) found that if the activation motif (LDYI) in the N-terminal domain of mouse Mrap1 (Figure 1) was replaced with alanine residues, the activation of MC2R was blocked. Furthermore, a single alanine substitution of the $\mathrm{Y}$ residue in the mouse Mrap1 LDYI motif resulted in a 50\% drop in activation. Note that similar activation motifs are present in the N-terminal domains of the chicken and zebrafish MRAP1

TABLE 1 | Summary of the interactions between human melanocortin receptors and human MRAP1 $\alpha$ and human MRAP2.

\begin{tabular}{|c|c|c|c|c|}
\hline & \multicolumn{2}{|c|}{ MRAP1 $\alpha$} & \multicolumn{2}{|c|}{ MRAP2 } \\
\hline & Trafficking & Activation & Trafficking & Activation \\
\hline MC1R & Not required & Not required & Not required & Lowers \\
\hline MC2R & Facilitates & Required & Facilitates & Required \\
\hline MC3R & Not required & Lowers & Not required & Lowers \\
\hline MC4R & Restricts & Lowers & Restricts & Lowers \\
\hline MC5R & Restricts & Lowers & Restricts & Lowers \\
\hline
\end{tabular}

Chan et al. (17) expressed individual human melanocortin receptors in $\mathrm{CHO}$ cells either in the presence or absence of either human MRAP1 $\alpha$ or human MRAP2, and measured either trafficking to the plasma membrane or activation with human ACTH (1-39) (MC2R; single dose 10-6 M) or NDP-MSH (MC1R, MC3R, MC4R, MC5R: single dose 10-9 M). For the trafficking experiments, "not required" indicates that co-expression with an MRAP had no negative or positive effect on trafficking to the plasma membrane relative to CHO cells transfected with only the melanocortin receptor. "Facilitates" indicates that the receptor did not translocate to the plasma membrane in the absence of the MRAP. "Restricts" indicates that there was a decline in trafficking to the plasma membrane when the receptor was co-expressed with an MRAP. For activation experiments, "not required" indicates that co-expression with an MRAP had no negative or positive effect on activation relative to CHO cells transfected with only the melanocortin receptor. "Requires" indicates that the receptor could not be activated when expressed alone in $\mathrm{CHO}$ cells. "Lowers" indicates that there was a statistically significant drop in activation when the receptor was coexpressed with an MRAP. 


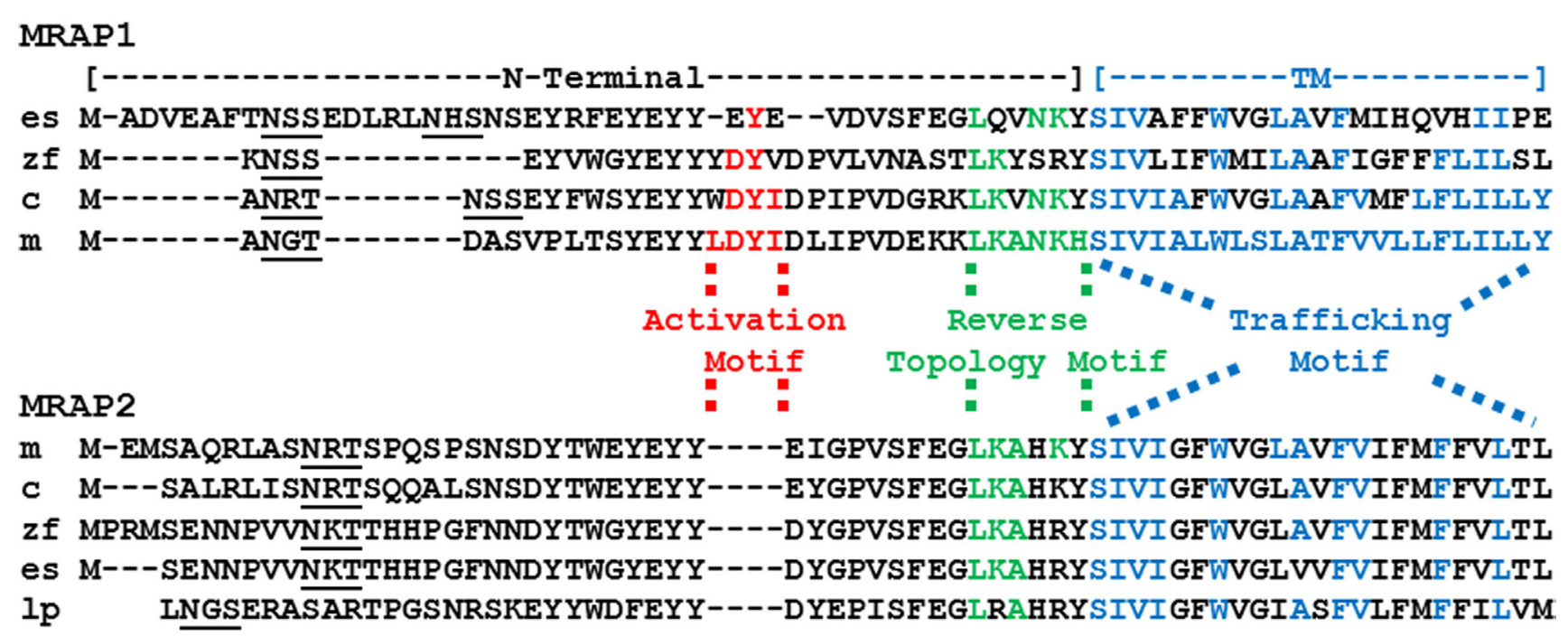

MRAP1

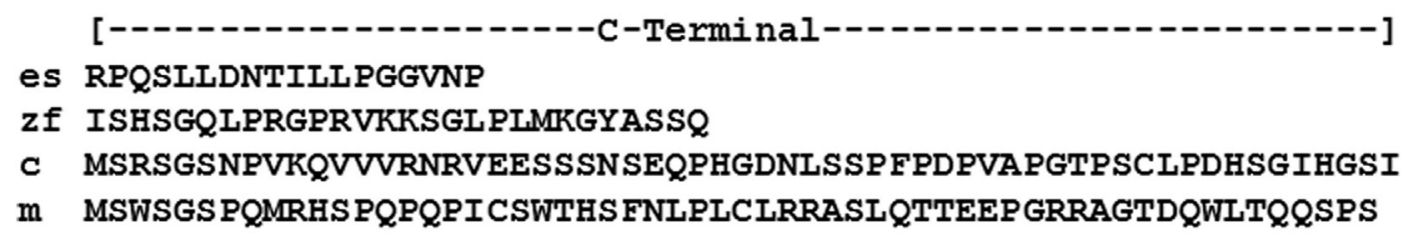

\section{MRAP2}

m LTKTGAPHQDNAESSERRFRMNSFVSDFGKPLESDKVFSRQGNEESRS LFHCYINEVEH.
c LTKTGAPHQENTESSEKRFRMNSFVADFGRPLESERVFSRQIAEESRS LFHFCINEVEH.
zf LTKTGAPHPEAAEPYEKRMRLTSCADGLGRQRETDGRTGLSRPLLEES RSLFHCYINEE.
es LTKTGAPHQENVDLPAKQHRMNGF SVGYPMLQKPDKAFVHRVSEESRS LFHCYVNEVGH.
lp LVRSGV

FIGURE 1 Amino acid sequence alignment of MRAP1 and MRAP2 paralogs. The amino acid sequences of mouse (m) MRAP1 (NP_084120.1), zebrafish ( $\mathrm{z}$ ) MRAP1 (XP001342923.2), chicken (c) MRAP1 (XR_001470382) elephant shark (es) MRAP1 (XM_007903550.1), mouse (m) MRAP2 (XP_006511239.1), chicken (c) MRAP2 (XP_015140201), zebrafish (Zf) MRAP2a (XP_001342923.4), elephant shark (es) MRAP2 (XP_007906624.1), and lamprey (Ip) MRAP2 (FAA00710.1) were aligned to the sequences of mouse MRAP1 and mouse MRAP2, respectively. Note that only a partial sequence for lamprey (Petromyzon marinus) MRAP2 has been reported (1). In addition, only the partial C-terminal sequences for the MRAP2 orthologs are presented. Predicted N-linked glycosylation sites are underlined. Note that there are two potential $\mathrm{N}$-linked glycosylation sites in the putative elephant shark MRAP1 amino acid sequence. The amino acids in the activation motif for mouse MRAP1 are highlighted in red. Conserved amino acid positions in the proposed activation motifs of the chicken, zebrafish, elephant shark MRAP1 orthologs are also highlighted in red. The amino acids in the reverse topology motif of mouse MRAP1 were highlighted in green. Conserved amino acid positions in the reverse topology motif of chicken, zebrafish, elephant shark, mouse, and lamprey MRAP1 and MRAP2 sequences, respectively, were also highlighted in green. Finally, the amino acids in the transmembrane domain of mouse MRAP1 are highlighted in blue, and the conserved amino acid positions in the chicken, zebrafish, elephant shark, mouse and lamprey MRAP1 and MRAP2 sequences, respectively, were also highlighted in blue.

orthologs (Figure 1). In addition, a recent study indicated that alanine substitution of the DY residues in the YDYV motif of zebrafish MRAP1 blocks activation of MC2R (24).

While it appears that the direct interaction of mammalian MRAP2 orthologs with mammalian MC2R orthologs might be pharmacological rather physiological [Table $1 ;(8,9,21)$ ], there are cells such as mouse adipocytes (25) and embryonic mouse adrenal cortex cells (26) that co-express Mrap2 as well as Mc2r and Mc5r. Sebag and Hinkle (27) found that when human MC5R and mouse Mrap2 were co-expressed in $\mathrm{CHO}$ cells, the trafficking of human MC5R to the plasma membrane decreased. The implication of these experiments was that by decreasing the number of MC5 receptors on the plasma membrane, Mrap2 would make the target cells more selective for stimulation by $\mathrm{ACTH}$, rather than $\alpha$-MSH. Since, MC2R and MC5R are co-expressed in chicken adrenal cortex cells (28), frog interrenal tissue (23), and rainbow trout interrenal tissue (29), an interaction between MC5R and MRAP2 could have physiological implications for 
non-mammalian vertebrates as well. Hence, an evaluation of the pharmacological interactions of MC5R and MRAP2 orthologs with respect to trafficking to the plasma membrane and ligand selectivity in these species is warranted.

When considering a physiological role for MRAP2, a promising area of study has been the interaction between MRAP2 and MC4R in the modulation of feeding behavior by neurons in the hypothalamus (30). In both zebrafish (31) and mice (32), endogenous MRAP2 orthologs appear to play roles in the ligand sensitivity of the MC4 receptor. For example, Asai et al. (32) observed that when mouse Mc4r and Mrap2 are co-expressed in HEK-293 cells, Mc4R has a higher sensitivity for $\alpha-\mathrm{MSH}$; an outcome that would decrease feeding activity in vivo. Conversely, in mice in which the Mrap2 gene was selectivity deleted from neurons in the hypothalamus, the result was an obese phenotype. While the implications of these results are intriguing from a biomedical perspective, it appears that for mammals there may be species specific difference in the regulation of MC4R. For example, Kay et al. (33) observed that co-expression of human MC4R and human MRAP2 in HEK-293 cells had no effect on ligand sensitivity. However, a shift in ligand sensitivity was observed when human MC4R was co-expressed with human MRAP $\alpha$. Clearly, studies are needed on other tetrapods (i.e., amphibians, reptiles, and birds) are needed to determine the role that MRAP2 may play in modulating the ligand selectivity of MC4R in the regulation of feeding behavior in these organisms.

A more complex mechanism for the role of MRAP2 in regulating feeding behavior has been observed for the zebrafish $(31,34)$. As a result of a teleost-specific genome duplication [3R event; (35)], two paralogs of the mrap2 gene (mrap2a and mrap2b) are present in the zebrafish genome (20). Furthermore, the expression of these paralogs appears to be developmentally regulated. Sebag et al. (31) report that during the larval stage of development, MRAP2a lowers the ligand sensitivity of zebrafish MC4R (as measured by $V \max$ ), and as a result the animal eats more; an outcome that would favor growth. During larval development, the expression levels of the zebrafish mrap $2 b$ gene are low. Conversely in the adult stage, zebrafish mrapb gene expression is elevated, and zebrafish mrapa gene expression declines. Sebag et al. (31) also report that co-expression of zebrafish MC2R and zebrafish MRAP2 in HEK-293 cells increases the sensitivity of zebrafish MC4R for $\alpha-\mathrm{MSH}$. These results are interpreted as giving the adult zebrafish fine control over food consumption; a trait that would be considered adaptive (31). Hence, it would appear that zebrafish $\mathrm{MRAPb}$ is functioning in a manner analogous to mouse Mrap2 (32). However, Aguilleiro et al. (34) observed that co-expression of zebrafish MC4R and zebrafish MRAP2a in HEK-293 cells resulted in a higher sensitivity of the zebrafish MC4R for ACTH as compared to $\alpha-\mathrm{MSH}$. The latter study proposes that ACTH may be playing a role in the control of feeding behavior, and that role can be influenced by the expression levels of zebrafish MRAP2a. In the later study, the in vitro effect of zebrafish MRAP2b on zebrafish MC4R ligand selectivity was not apparent. Finally, zebrafish MRAP2a had no negative or positive effect on the trafficking of zebrafish MC4R to the plasma membrane $(31,34)$; whereas zebrafish MRAP2b appeared to increase the surface expression of zebrafish MC4R (31). Hence, there appears to be species-specific differences in way the MC4R orthologs respond to interaction with MRAP2 (See Table 1) That said, at the molecular level it is not clear which domain(s) of MRAP2 (MRAP2a or MRAP2b) are making contact with MC4R to alter ligand selectivity. The possibility of an "activation motif" in MRAP2 orthologs, analogous to the activation motif in MRAP1 orthologs, has not been investigated.

In terms of the evolution of the MRAP gene family, an earlier review concluded that MRAP2 was the ancestral "MRAP" (1). This conclusion was based on the apparent absence of MRAP1 orthologs in the genomes of a cartilaginous fish (Callorhinchus milii, the elephant shark) and the lamprey (Petromyzon marinus), and the presence of MRAP2 orthologs in both these species. In this scenario, the duplication of the ancestral mrap gene may have occurred in the bony fishes following the divergence of the ancestral cartilaginous fishes and the ancestral bony fishes (36) over 420 million years ago. However, recent annotation of the elephant shark genome project ${ }^{1}$ revealed a cDNA (accession number: XM_007903550.1) that Blast analysis ${ }^{2}$ has identified as an MRAP1 ortholog. The deduced amino acid sequence of the putative elephant shark MRAP1 ortholog is presented in Figure 1. The putative elephant shark MRAP1 has a reverse topology motif (LQVNKY), and the TM region has 39\% amino acid sequence identity with the mouse MRAP1 TM region. The C-terminal domain of the putative elephant shark MRAP1 is very short relative to the other MRAP1 orthologs. However, Sebag and Hinkle (18) have shown that the C-terminal of mouse MRAP1 is not required for either trafficking or activation of mammalian MC2R orthologs. The N-terminal domain of the putative elephant shark MRAP1 is nearly $43 \%$ longer than the other MRAP1 orthologs in Figure 1. By inserting gaps, it was possible to align these sequences and identify a putative activation motif (EYE) in the putative elephant shark MRAP1. The presence of the $\mathrm{Y}$ residue in this domain is particularly interesting, given the importance of this residue for mammalian and teleost MRAP1 orthologs $(18,24)$.

From a phylogenetic/evolutionary perspective, the detection of the putative cartilaginous fish MRAP1 ortholog fills a gap. The elephant shark is in Subclass Holocephali (Class Chondrichithyes), and it is very probable that mrapl orthologs are present in the genomes of members of Subclass Elasmobranchii (i.e., sharks and rays). Hence, mrap1 and mrap 2 paralogs may have been present in the genome of the ancestral gnathostomes (Figure 2). Given these assumptions, the evolution of the mrap gene family may have involved the following scenario. In the ancestral agnathan vertebrates that underwent the $2 \mathrm{R}$ genome duplication event, the ancestral mrap gene would have been duplicated to yield the mrap 1 and mrap 2 genes, and these paralogous genes presumably would have been distributed on separate chromosomes. Currently, mrap 1 and mrap 2 genes have been found on separate chromosomes in the various gnathostome genome databases where chromosomes maps are available. ${ }^{3}$ Among extant $2 \mathrm{R}$

${ }^{1}$ http://esharkgenome.imcb.a-star.edu.sg

${ }^{2}$ https://blast.ncbi.nlm.nih.gov/Blast.cgi

${ }^{3}$ http://ensemble.org 


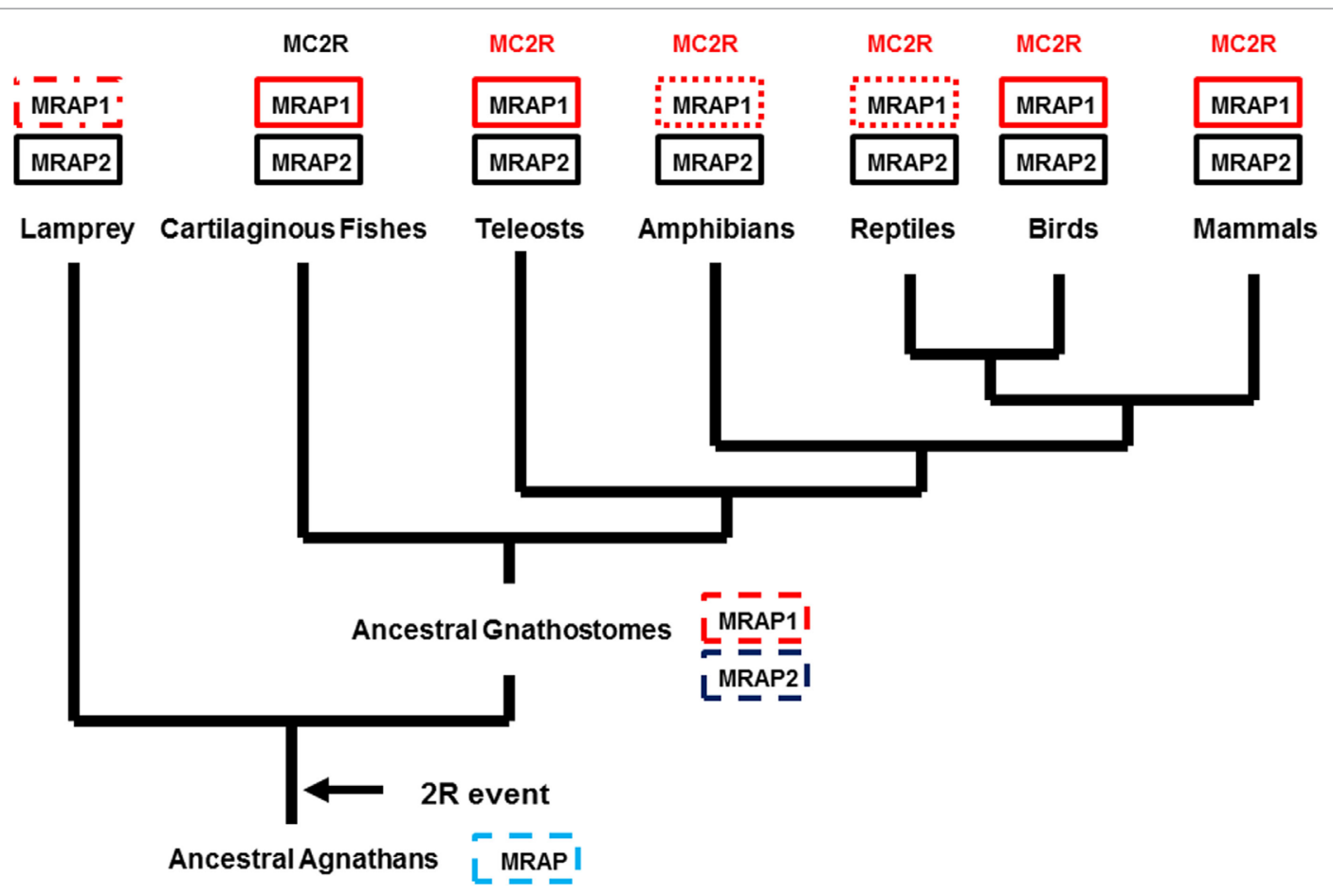

FIGURE 2 | Proposed evolution for the MRAP Gene Family. The evolutionary tree presented in this figure assumes that there was an ancestral mrap (MRAP) gene in the genome of ancestral agnathans. Following the 2R genome duplication event, two paralogous mrap genes emerged (MRAP1 and MRAP2) and are present in the genomes of many extant $2 \mathrm{R}$ chordates. A solid black box indicates that the gene has been reported in the respective taxa. A box with a dashed line border indicates a gene that is predicted, but has not been detected (i.e., lamprey MRAP1) or the organism is extinct (e.g., ancestral agnathans, ancestral in gnathostomes). A box with a dotted border indicates a taxonomic group in which MRAP1 is required for the functional expression of MC2R, but a MRAP1 sequence has not been identified in the genome of a representative from that taxonomic group.

vertebrates (Figure 2), an mrap1 ortholog has not been detected in the current version of the lamprey genome project ${ }^{4}$ (Figure 2). Whether the absence of this ortholog represents the incomplete state of the lamprey genome project, or a secondary loss of the ortholog cannot be determined at this time. In addition, mrap1 orthologs have not been detected in the genomes of either the frog, Xenopus tropicalis or the reptile, Anolis carolinensis. However, the MC2R orthologs for both species requires co-expression with a tetrapod MRAP1 ortholog for functional expression in $\mathrm{CHO}$ cells $(21,37)$. It would appear that either the $X$. tropicalis and A. carolinensis genome projects are not complete, or some other accessory protein is utilized in these species.

From a pharmacological perspective, the presence of the putative elephant shark MRAP1 ortholog is perplexing. An earlier study had shown that the elephant shark MC2R ortholog could be functionally expressed in $\mathrm{CHO}$ cells in the absence of co-transfection of an exogenous mrap1 cDNA (38). Elephant shark MC2R could be stimulated in a dose-dependent manner by either human ACTH (1-24) or by dogfish (Squalus acanthias) ACTH (1-25). More recently, a MC2R cDNA cloned from the genome of the stingray, Dasyatis akajei, was also functionally expressed in $\mathrm{CHO}$ cells in the absence of co-transfection of an exogenous mrap1 cDNA (39). The stingray MC2R ortholog also

${ }^{4}$ http://www.ensembl.org/Petromyzon_marinus/Info/Index could be stimulated by stingray ACTH (1-24) and stingray DesAcetyl- $\alpha-\mathrm{MSH}$. Hence, there are several issues with respective to the putative elephant shark MRAP1 that need to be resolved. It will be important to determine whether the elephant shark mrap1 mRNA is expressed in the same cells as elephant shark mor mRNAs. In addition, pharmacological studies are needed to determine whether co-expression of cartilaginous fish MCR orthologs with the putative elephant shark MRAP1 ortholog have any effect on either trafficking of the MCR orthologs to the plasma membrane or sensitivity to melanocortin ligands.

\section{LIGAND SELECTIVITY OF MC2R ORTHOLOGS}

Several studies have shown that the MC2R orthologs of teleosts and tetrapods (Figure 2) require co-expression with a corresponding MRAP1 ortholog. Perhaps as a result of this interaction, and the intrinsic tertiary features of these $\mathrm{MC} 2 \mathrm{R}$ orthologs, all of these receptors can only be activated by ACTH, and not by any $\mathrm{MSH}$ sized ligand (19-21, 37, 40). Nearly 40 years ago, analog studies on mammalian ACTH sequences revealed the dual importance of the $\mathrm{H}^{6} \mathrm{~F}^{7} \mathrm{R}^{8} \mathrm{~W}^{9}$ motif and the $\mathrm{K}^{15} \mathrm{~K}^{16} \mathrm{R}^{17} \mathrm{R}^{18}$ (tetrabasic) motif in ACTH for the activation of the "ACTH" (MC2R) receptor on mammalian adrenal cortex cells (41). These same features are required for the activation of $\mathrm{MC} 2 \mathrm{R}$ on the interrenal and 
adrenal cortex cells of non-mammalian tetrapods and teleosts as well (42). Although, teleost and tetrapod $\alpha$-MSH sequences have the $\mathrm{H}^{6} \mathrm{~F}^{7} \mathrm{R}^{8} \mathrm{~W}^{9}$ motif, these ligands lack the tetrabasic motif, and as a result are incapable of activating either teleost or tetrapod $\mathrm{MC} 2 \mathrm{R}$ orthologs. By contrast, the teleost and tetrapod MC1R, MC3R, MC4R, and MC5R paralogs can be activated by either ACTH or the MSH-sized polypeptides derived from POMC with varying potencies $(10,42,43)$. It would appear that teleost and tetrapod MCR paralogs all have an HFRW-binding site, and MC2R orthologs have an addition R/KKRR-binding site. These generalizations apply for the ligand selectivity properties of the MCRs of cartilaginous fishes (class Chondrichthyes) with one notable exception.

Studies on the ligand selectivity of dogfish, Squalus acanthias (order Squaliformes, subclass Elasmobranchii), MC3R, MC4R, and MC5R paralogs (44-46), and the MC1R, MC3R, MC4R, and MC5R paralogs of the stingray, D. akajei [order Rajiformes, subclass Elasmobranchii; (39)] found that these MCR paralogs could be activated by either ACTH or MSH-sized ligands in a manner analogous to the corresponding MCR paralogs in teleosts or tetrapods. Hence, these paralogs have an HFRW-binding site. However, the MC2R ortholog of the stingray, D. akajei, and the MC2R ortholog from the elephant shark, C. milii (order Chimaeriformes, subclass Holocephali) could also be activated by either ACTH or MSH-sized ligands $(38,39)$, and as noted in Phylogeny and Proposed Evolution of the MRAPs, both of these MC2R orthologs could be functionally expressed in $\mathrm{CHO}$ cells without co-expression of an exogenous mrap1 cDNA. The two cartilaginous fish MC2R orthologs, from different subclasses of the cartilaginous fishes, have ligand selectivity properties more similar to MC4R paralogs, and most likely have only a HFRWbinding pocket. This apparent feature for the cartilaginous fishes MC2R orthologs would be quite distinct from teleost and tetrapod MC2R orthologs. Whether the ligand selectivity properties zMC2R M-- SMC2R MPDMMIPGYGTLLDSNGIL PMP PDATIS PHS HPT ISPWLPYGT EVVIDT INQTNMNAT EEC SQIEIP TEVYLI LGLVSL LEN LLVVIAVLKNKKLHF EMC2R M-_-_-_-_-_-_-_-_-_-SGADT SAS PWLANVTTAVMNTSG FMNGSGGICRQLEIP LEVYLI LGGVGMLEN LLVIIAVVNNRN LHS SMC4R M-1-

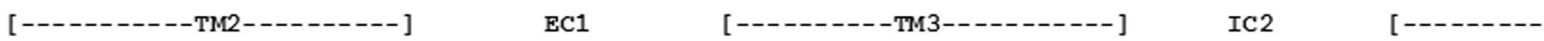

hMC2R PMYFFICSLAISDMLGSLYKILENI LII LRNMGY LKPRGSFETTADDIIDSLFVLSLLGSIFSLSVIAADRYITIFHALRYHSIVTTRRTVVVLTVI 194

zMC2R PMYCFICNLAVFNTIS SFSKALENI LLL FKDAGR LNSRGP FELKIDDIMDSL LCMCFLGSI FSI LAIAVDRYI SIF HALRYHMLMTMRRVLIIL FTI SMC2R PMYF FICSLAVSD ILLCLSKAWEAFTIS LVNNHEDLFTQT FLLSLDNVFDTLICI SFLASI FNLAAI TTDRYI SIFHCLRYHNTMTGKRVAFAIAGI EMC2R PMYLFICSLAMADMLVSVGKASEAVIIF LDQNSHLL-TET LIDHLDYLFDSL ICI SLIASI LSLGAIATDRYLTIFHALRYHQTMTVKRAALII SAL SMC4R PMYFFICSLAVADMLI SVSNAWETITIAMLKSRHLLAQDKLIKSIDNVFDSVICS SLLASICSLLAVAVDRYITIFYALRYHNTMTVRRALTVIAGI $\star$

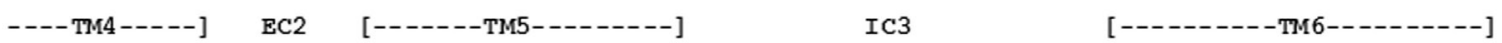

hMC2R WTFCTGTGITMVI FSHHVP TVITFT SLF PLMLVF ILC LYVHMF LLARSH--- --- TRKISTLPRANMRGAITLTI LLGVFIFCWAPFVLHVLLMTF 291 zMC2R WVLCGTS GALMVG FEAATVKI FFIVLF FTA LLL I LL LYVHMF LLARHHANR IASMPGAOAQHRKSG LRGALT LTI LIGVFVACWAPF SLH LLIMMI SMC2R WVFC TAT GILMIN FHN SQGIIS FYI IFF LLSVVL IVS LYIYMF LLAQMH -ARKIRILP GHTAHQGINFKGAFTVTVLLGVFI FCWAPL SLHFIL FLL EMC2R WTFCTFS GSF I IKFNRKNAFPGSLI TMY FTT LFVIVS LYVYMF LLARRH -AQCIRSLP GRVHQGTS LKGAIT LTI LLG IF I ICWAPF FLH LI LVLA SMC4R WAVCIGS GILFIIYSE STTAVICLIAMF FAMLAIMAS LYVHMFMLARLH LKRIAALPS SGA ICQAANMKGAIT LT I LLGVFVVCWAPF FLH LI LMIS

$$
\text { EC3 [------TMT---------] C-TERMINAL }
$$

hMC2R CPSNPYCACYMSLFOVNGMLTMCNAVIDPFIYAFRSPELRDAFKKMIFC SRYW

ZMC2R CPENPYCECYRSLFQLHVVLLVSHAVID PAIYAFRSVELRNTYKKMLLS SASRICKRCA

SMC2R CPSD PYCACFMS LFOIDLI FIMCHS IID PLI YAF RDPELSNTFKXMMFCHKKQWY FHASPS FLN I

EMC2R CPSNPYCTCYMSLFQVDLI LIMCNSIID PLI FAFRSPELRNTFKKMCIC FNKQLY

SMC4R CPRNPYCICFMSHFNMYLILILCNS IID PLI YAFRSQEMRKTFKEI ICCYSLRGS CDL LSNINTH

\begin{tabular}{lc} 
A) Overall \& Amino acid Identity for all \\
B) Sequence identity by region \\
\& Amino Acid Identity \\
\cline { 2 - 2 } N-TERMINAL & 2 \\
TM1 & 35 \\
IC1 & 83 \\
TM2 & 46 \\
EC1 & 5 \\
TM3 & 58 \\
IC2 & 81 \\
TM4 & 22
\end{tabular}

\begin{tabular}{lc} 
& \& Amino Acid Identity \\
\cline { 2 - 2 } EC2 & 11 \\
TM5 & 33 \\
IC3 & 24 \\
TM6 & 76 \\
EC3 & 57 \\
TM7 & 55 \\
C-TERMINAL & 39
\end{tabular}

FIGURE 3 | Amino Acid Alignment of MC2R Orthologs. The amino acid sequences of human (h) MC2R (NP_001278840.1), zebrafish (z) MC2R (XP_00518229.1) stingray (s) MC2R (LC108747), elephant shark (e) MC2R (FAA704.1), stingray (s) MC4R (LC108749) were aligned, and amino acid positions in which four of the five sequences were identical are marked in red. The position of critical amino acids in the HFRW-binding site of MC4R orthologs (47) are marked with a star. The overall percent primary sequence identify $\mathbf{( A )}$ and the percent identity within each domain $\mathbf{( B )}$ are presented. 
of the cartilaginous fishes MC2R orthologs are an ancestral trait or a derived trait unique to the cartilaginous fishes is not clear at this time.

In any event, there should be distinct sites within the teleost/ tetrapod MC2R orthologs and the cartilaginous fishes MC2R orthologs that can account for the ligand selectivity properties of these receptors. In this regard, a comparison of MC2R orthologs with an MC4R paralog my reveal these potential sites. As shown in Figure 3, the human, zebrafish, elephant shark, and stingray $\mathrm{MC} 2 \mathrm{R}$ amino acid sequences could be aligned to the stingray MC4R sequence by inserting a minimum of two gaps. The positions of critical residues in TM2, TM3, TM6, and TM7 that correspond to the HFRW-binding site for a MC4R ortholog (47) are marked with a star. For the teleost and tetrapod MC2R orthologs, six of these sites are conserved, and for the cartilaginous fishes MC2R orthologs eight of these positions are conserved. Overall only $33 \%$ of the positions in this alignment are identical in at least four of the five sequences, however, there are very clear regions of primary sequence identity, which serve as markers for MCR-related sequences. The highly conserved regions (sequence identify greater than 50\%) include: IC1, TM3, IC2, TM6, EC3, and TM7. Moderately conserved regions (sequence identity greater than 35\%) include: TM1, TM2, and the C-terminal domain. The highest primary sequence divergence $(<15 \%)$ was observed for the N-terminal domain, EC1, and EC2.

Previous studies used chimeric proteins of human MC2R and human MC4R to analyze the functions of these regions. For example, Fridmanis et al. (48) observed that replacing the N-terminal domain of human MC4R with the N-terminal domain of human MC2R inhibited trafficking of the chimeric MC4R protein to the plasma membrane. However, since the N-terminal of stingray MC4R is nearly the same length as the human MC2R domain (Figure 3), and the stingray receptor could be functionally expressed in CHO cells (39), length alone may not be a factor in influencing trafficking to the plasma membrane. Hinkle et al. (49) observed that exchanging the TM2/EC1/TM3 region of human $\mathrm{MC} 2 \mathrm{R}$ with the corresponding region of human $\mathrm{MC} 4 \mathrm{R}$ resulted in a chimeric MC2R protein that could be activated by either ACTH or NDP-MSH. Presumably making a similar chimeric protein for human MC2R, but using the TM2/EC1/TM3 region of either elephant shark or stingray MC2R should yield the same outcome. Finally, Fridmanis et al. (48) observed that substitution of the TM4 and TM5 domains in human MC2R affected ACTH activation, and this region of human MC2R may be the KKRR-binding site. In support of the later conclusion, studies on naturally occurring mutations in the TM4/EC2/TM5 domain of human MC2R, and alanine substitution experiments point to the TM4/EC2/TM5 region as playing an important role in the activation of human MC2R [for review see Ref. (50)]. It would now seem advantageous to extend the chimeric protein paradigm to the cartilaginous fishes MC2R orthologs to determine whether exchanging the TM2/EC1/TM3 and TM4/EC2/TM5 domains of teleost/tetrapod MC2R orthologs with the corresponding domains in the elephant shark MC2R orthologs would make the cartilaginous fish MC2R chimeric proteins exclusively selective for $\mathrm{ACTH}$, and in the converse experiments, would the teleost/ tetrapod chimeric MC2R proteins have more permissive ligand selectivity properties. Given Malik et al. (51) observations on the importance of extracellular domains in human MC2R for interaction with mouse MRAP1, co-expression of these MC2R

\footnotetext{
A N-TERMINAL [--------TTM1---------] IC1 [--------TTM2--------

- MC2R M---------------------AVNETD CKEVKI PNE IFFAITMVS LTENLLVVVAVI KNKNLHSPMYCF ICS LALFNVLSSVSKAL MC5R MNSSDKMLMQGPLATSS SNSQSNFTD LPGKTKPTACEQVNIATEVF L TLG IVS LLENILVICAIVKNKNLHSPMYFFVCS LAVADMLVSVSNAW ----] EC1 [--------TM3---------] IC2 [---------TM4--------] EC2 MC2R ENTMLVFTDAGRLD SRGKFE TKT DDVMDT LLCMSF TGS IFS LSA IAVDRY ITI FHA LRYHNIMTMKRVAVI LGS IWT FCAGSGVVMIIF FRA TV 186 MC5R ETIVIYLLNNRQLIMEDNFI RQVDNVFDSMIC ISVVASMCS LLA IAVDRYVTI FYA LRYHNIMTVRRAGFI IAG IWT FCT GCG IVF IIYSDT TP [----TM5------] IC3 [---1--MC2R IMTCF IALFLVSLVLIL ILYVHI FQLART HVWKIASLPG-NRSR OKNNMKGAI TLT I LFGVF I ICWSPFFFHLL ILMVCP LNPYCECYRSLF QV 279 MC5R VI ICL I SMFFGMLVLMA S YY SHMFLLARS HVKRIAALP GYNSIHQRASIMKAAVTLT ILLGIF IVCWAPFFLHLI LMI SCP RNL YCVCFMSHFNM ------TMT---------] C-TERMINAL

MC2R HVILLMCNAVIDPVIYAFRSAELRNT LRKMFFCSGTRE PVS IICCDNQSVLSS LSI LFH LKQDNPT

MC5R YLILIMCNSVIDPLIYAFRS QE-----------MRKT FKE IICCYS LRNACG LPSKY

B N-TERMINAL [---------TM1--------- ] IC1 [---------TM2---- MC4R MNTTHHHG LIHNYHSRNFSS GAF TVNNDSNEKDSS SGCYEQLLI STEVFLTLG IVS LLENILVIAAIIKNKNLH SPMYFF ICS LAVADMLVSVS MC5R MNSS---DKMLMOG PLATSS SNSQSNFTD LPGKTKPTACEOVNIATEVFLTLG IVS LLENILVICAIVKNKNLHSPMYFFVCS LAVADMLVSVS ------ EC1 [--------TM3-------- ] IC2 [---------TM4---------]

MC4R NAWET IVMALITSGHLT IODNLI KNMDNVFDSMIC SSL LAS ICS LLA IAIDRY ITI FYA LRYHNIMTMRRAMMII ITT IWAFCT ISG ILF IIY SE 186 MC5R NAWET IVI YLLNNRQLIMED NFI RQVDNVFDSMIC ISVVASMCS LLA IAVDRYVTI FYA LRYHNIMTVRRAGFI IAG IWT FCT GCG IVF IIY SD

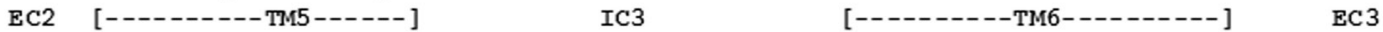

MC4R STTVIICLITMFFTMLALMASLYVHMFMLARLHMRIAALPGNGTIHQGANMKGAITLT ILLGVFVVCWAPFFLHLI LMIACPRNPYCVCFMS MC5R TT PVI ICL ISMFFGMLVLMA S LY SHMF LARSHVKRIAALPGYNSIHORA SMKAAVTLT IL LGIF IVCWAP FF LHLI LMI SCPRNL YCVCFMS [-------TM7-------] C-TERMINAL

MC4R HFNMYLILTMCNSVIDPLIYAFRSOEMRKTFKEIFCWYGLPGFCVCE LPSKY

MC5R HFNMY LILIMCNSVIDP LIYAFRSOEMRKTFKEIICCY SLRNAC--GLPSKY

FIGURE 4 | Amino Acid alignment of Gar MC2R, MC4R, and MC5R. The amino acid sequences of gar MC2R (ENSLOCT00000011667), gar MC4R (ENSLOCT00000022303), and gar MC5R (ENSLOCG00000018340) were aligned and positions that were identical are marked in red. (A) alignment of gar MC2R and gar MC5R; (B) alignment of gar MC4R and gar MC5R.
} 
chimeric proteins with a class-specific MRAP1 ortholog may reveal the domain within the MC2R orthologs that makes contact with MRAP1.

\section{MELANOCORTIN RECEPTOR GENOME AND GENE DUPLICATIONS}

The successive genome duplications during the radiation of the chordates theoretically should yield four paralogous genes in the genomes of extant cartilaginous fishes, non-teleost ray finned fishes, and tetrapods. However, in the genomes of the Japanese stingray (39), the spotted gar $^{5}$, or the mouse (6), there are five paralogous MCR genes. The conclusion drawn from these observations is that one of the paralogous $m c r$ genes underwent a local gene duplication (52). While there is general agreement that the $m c 5 r$ gene was the result of the local gene duplication, the original $m c r$ paralog that was duplicated has not been resolved. The issues

${ }^{5} \mathrm{http}: / /$ www.ensembl.org/Lepisosteus_oculatus/Info/Index associated with the origin of the $m c 5 r$ gene can be seen in the spotted gar (sg) genome. Chromosome mapping indicates that the sgmc1r gene is located on chromosome 21, the sgmc $2 r$ gene is located on chromosome 11, the sgmc3r gene is located on chromosome 18, the sgmc4r gene is located on chromosome 9, and the sgmc5r gene is also located on chromosome 11 . The presence of paralogous genes on different chromosomes is considered an indication of a genome duplication event(s) (4). The presence of two genes on the same chromosome is generally construed as a result of a local gene duplication. In this regard, synteny studies found that the $m c 2 r$ and the $m c 5 r$ genes were on the same chromosome in the genomes of teleost fishes, the chicken (Gallus gallus), and several mammals $(43,52,53)$. Based on these observations, it seemed reasonable to conclude that the $m c 2 r$ and $m c 5 r$ genes were the result of a local gene duplication $(54,55)$. In this scenario, the paralogous $m c 2 r$ and $m c 5 r$ genes would accumulate mutations independently, and based on selection pressures diverge in terms of amino acid sequence, and perhaps in terms of function. The divergence in amino acid sequence can be seen from an alignment of gar MC2R and gar MC5R (Figure 4A). The amino acid identity for the two paralogs is $42 \%$. From an evolutionary

A

N-TERMINAL

[---------TM1----------] IC1

hMC2R M--SMC2R MPDMIPGYGTLLDSNGIL PMP PDATIS PHS HPT ISPWLPYGT EVVIDT INQTNMNATEEC SQIEIPTEVYLI LGLVSL LEN LLVVIAVLKNKKLHF

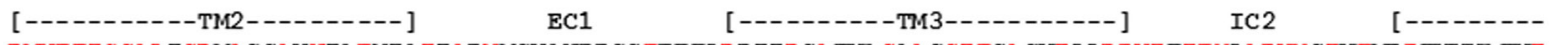
hMC2R PMYFFICSLAISDMLGSLYKILENILIILRNMGYLKPRGSFETTADDIIDSLFVLSLLGSIFSLSVIAADRYITIFHALRYHSIVTTRRTVVVLTVI 194 SMC2R PMYF FICSLAVSD ILLCLSKAWEAFTIS LVNNHEDLFTQT FLLSLDNVFDTL ICISFLASI FNLAAITTDRYISIFHCLRYHNDMTGKRVAFAIAGI $\star$

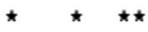

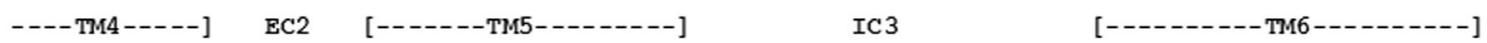

hMC2R WTFCTGTGITMVI FSHHVP TVITFT SLF PLMLVF ILCLYVHMF LLARSH--- --- TRKISTLPRANMKGAITLTILLGVFIFCWAPFVLHVLLMTFC 291 SMC2R WVFC TAT GILMIN FHN SQGIIS FYI IFF LLSVVL IVS LYIYMF LLAQMHARKIRI LPGHTAHQG INF KGAFTVTVL LGVFIF CWAPLS LHF ILF LLC

$$
\text { EC3 [------TM7---------] C-terminal }
$$

hMC2R PSNPYCACYMSLFQVNGMLIMCNAVIDP FIYAFRSPE LRDAFKKMI FCSRYW

SMC2R PSDPYCACFMSLF QID LIF IMCHSI IDP LIYAFRDPE LSNTFKKMMCHKKQWYF HAS PSF LNI

B

N-TERMINAL

[--------TTM1--------- ] IC1

[----------T72---------- ]

EC1

GMC2R M------AVNETDCKEVKIPNEIF FAI TMVS LTENL LVVVAVIKNKNLHSPMYC FIC SLA LFNVLS SVS KALENTMLVFTDAGR LDS RGKFET KT ZMC2R MNPSAESPSS IHTDCAEVQVPGQVF LVIAVASLSENL LVIVAVIKNKNLHSPMYC FICNLAVFNTIS SFS KALENI LLLFKDAGR LNSRGP FELKI *

$$
\text { [--------TM3---------] IC2 [--------TMM4--------] BC2 [------TM5------- ] }
$$

GMC2R DDVMDTLLCMSFTGSIFSLSAIAVDRYITIFHALRYHNIMTMKRVAVILGSIWTFCAGSGVVMI IFFRATVDMTCF IALFLVSLVLIL ILYVHI FQ ZMC2R DDIMDSL LCMCFLGSIFSI LAIAVDRYI SIFHALRYHMLMTMRVL I I LFTIWVLCGT SGA LMVGFFEAATVKIFF IVLFFTALL LIL LLYVHMFL $\star \star \star \star$

IC3

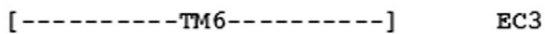

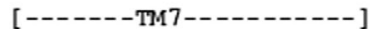
GMC2R LART HVWKIASLP GNRSRQKNNMKGAIT LTI LFGVFI ICWSPF FFHLLI LUVCPLNPYCECYRS LFQVHVILLMCNAVIDPVIYAFRSAELRNT LR ZMC2R LARH HANRIASMP GAAQHRKSGLRGALT LTI LIGVFVACWAPF SLHLLIMII CPENPYCECYRS LFQ LHVVLLVSHAVIDPAIYAFRSVELRNT YK $\star \star \star \star$

$$
\text { C-terminal }
$$

FIGURE 5 | Amino acid sequence identity of MC2R orthologs. (A) The amino acid sequences of human (h) MC2R and stingray (s) MC2R were aligned. (B) The amino acid sequences of gar (g) MC2R and zebrafish (z) MC2R (XP_005158229) were aligned. The position of critical amino acids in the proposed HFRW-binding site (47) are marked with a star. Amino acid positions that are identical are marked in red. 
perspective, the local gene duplication may have occurred after the $2 \mathrm{R}$ genome duplication event in the ancestral gnathostomes prior to the divergence of the ancestral cartilaginous fishes and the ancestral bony fishes.

However, Vastermark and Schioth (1) have pointed out that in phylogenetic analyses, MC5R orthologs form a clade with MC4R orthologs, and do not form a clade with MC2R orthologs. These observations have led to the conclusion that the $m c 5 r$ gene was the result of a duplication of the $m c 4 r$ gene (1). In support of this conclusion, an alignment of gar MC4R and gar MC5R indicates $70 \%$ sequence identity (Figure $4 \mathrm{~B}$ ). In this scenario, the presence of the $m c 2 r$ and $m c 5 r$ paralogous genes on the same chromosome of extant teleost and tetrapods could have been the result of an exchange of chromosome fragments in the last common ancestor to the ancestral ray-finned fishes (Class Actinopterygii) and the ancestral lobe-finned fishes (Class Sarcopterygii), the lineage which gave rise to the tetrapods, approximately 410 million years ago (56).
While either scenario (i.e., MC2R/MC5R or MC4R/MC5R) can be supported by the current evidence, there are at least two issues that neither scenario adequately addresses. As shown in Figure $5 \mathrm{~A}$, a comparison of stingray MC2R and human MC2R, vertebrates that last shared a common ancestor over 420 million years ago, the amino acid sequence identity is $37 \%$ (positions in red). Given the apparent role of the Hypothalamus/Pituitary/ Adrenal (HPA) axis and the Hypothalamus/Pituitary/Interrenal (HPI) axis in maintaining the fitness of vertebrates (57-60), this lack of primary sequence conservation is difficult to comprehend. While divergence is expected, this degree of divergence is difficult to rationalize. It would appear that during the radiation of the gnathostomes, the $m c 2 r$ gene sequence has drifted to the current state, while still maintaining functional capabilities.

For ray-finned fishes, such as the gar or zebrafish (Class Actinopterygii), MC2R primary sequence conservation is higher (55\%; Figure 5B), and this condition may reflect the close interaction with MRAP1. That interaction most likely

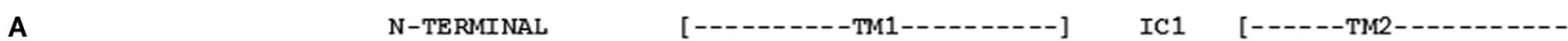 hMC5R MNSS FHLHFLDLNLNA TEGNLS GPNVKNKSS PCEDMG IAVEVF LTL GVI SLLENI LVI GAIVKNKNL HSPMYF FVC SLAVADMLVSMS SAWE SMC5R MN-----LTKLSLMSVTLAEAMVNGTRS STALCEQVSVAVEVF LILGII SLLENI LVIAAI IKNRNLHSPMYF FVC SLAVADMLVSVSNAWE

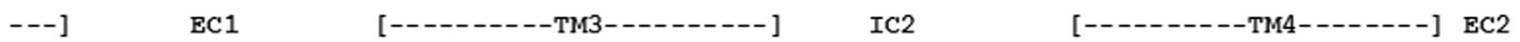 \\ hMC5R TITIYLLNNKHLVIADAFVRHIDNVFDSMIC ISVVASMCS LLA IAVDRYVTI FYALRYHHIMTARRS GAI IAG IWAFCT GCG IVF ILYSEST SMC5R TIVITLLHSRHLVVKD SFVKHVDNVFDSMIC TSVVASMCS LLA IAVDRY ITI FYALRYHHIMSMKRAAFI IAG IWALCI GCG IIF IIY SES P

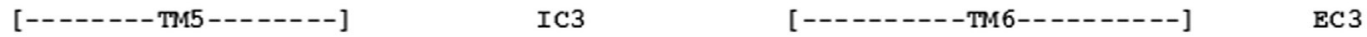

hMC5R YVILCLI SIMF FAMLFL LVS LYIHMF LLARTHVKR IAA LPGASSARQRTSMQGAVTVTMLLGVFTVCWAPF FLH LTLMLS CPQNLYCSRFMSH SMC5R TVIICLVTMFF FMLLIMAS LYSHAF LLARSHAKR IAAMSS SNS IHQQASMKGAIT LTI LLG IFIVCWAPL FLH LILMIS CPRNLYCTC FMSH [-------TPM --------] C-TERMINAL

hMC5R FNMY LIL TMCNSVMDP LIYAFRSQEMRKTFKEIICCRGFR IAC SFPRRD SMC5R FNLYLIL TMCNSI IDPLIYSFRSQEIRKTLKEIICCHSLRAVCRLTVK $\star \star \star$

B

N-TERMINAL [---------T7M1---------] IC1 [------T7\%2-GMC5R MNSS--------DKMLMOG PLATSS SNS QSNFTD LPGKTKPTACEOVNIATEVF L TLG IVS LLENILVICAIVKNKNLHSPMYFFVCS LAVA FMC5R MNTSHRS SDPQEG IMGNSTWNP LSYQPNFTL SPP LLPKTKTAACEQ LHIAIEVFL TLG IIS LLENILVDMAIVKNKNLH SPMYFFVCS LAVA

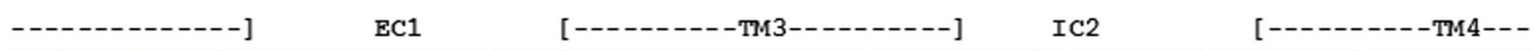

GMC5R DMVLVSSNAWETIVIY LLNNRQLDMEDNFIRQVDNVFDSMICI SVVASMCSL LAIAVDRYVTIFYALRYHNDMTVRRAGFIIAGIWTFCTGC FMC5R DMLVSVSNASETI IIY LLNNKQ LIAEDHLIRQLDNVFDSMICI SVVASMCS L LAIAVDRYVTIFYALRYHNIMTVRRAGCIIGGIWTFCTGC

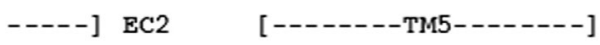
IC 3

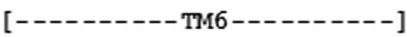
GMC5R GIVF IIYSDT TPVIIC LISMFFGMLVMASL YSHMFL LARSHVKRIAAL PGYNSI HQRASMKAAVTL TIL LGI FIVCWAPFF LHL ILMISC P fMC5R GIVF IIYSDT TPVIIC LVCMFF AML LIMASLYSHMFMLARSHVKRIAALPGSNSI HQRASMKGAITLTIL LGIFIICWAPFF LHL ILMISCP

EC3 [-------TM7------- ] C-TERMINAL

GMC5R RNLYCVC FMSHFNMYL ILIMCNSVIDPL IYAFRS QEMRKT FKE I ICCYS LRNACGLPSKY AMC5R RNLYCMC FMSHFNMLILIMCNSVIDPLIYAFRSQAMRT FKE IIFCYSLRNTCSTICTLPGKY

FIGURE 6 | Amino Acid Sequence Identity of MC5R Orthologs. (A) The amino acid sequences of human (h) MC5R (NP_ 005904.1) and stingray (s) MC5R (AY562212) are aligned. (B) The amino acid sequences of gar (g) MC5R and Takifugu rubripes (f) MC5R (AA06553.1; fugu) were aligned. The position of critical amino acids in the proposed HFRW-binding site (47) is marked with a star. Amino acid positions that are identical are marked in red. 
started in the ancestral bony fishes, and while the interaction may not have "rescued" MC2R functionality, the interaction appears to have stabilized the functional capabilities of teleost and tetrapod MC2R orthologs. Tetrapod MC2R orthologs show a similar level of primary sequence conservation. As a result, selection pressures on teleost and tetrapod MC2R orthologs may involve maintaining the close interaction between MRAP1 and MC2R. For the cartilaginous fishes, the MRAP1/MC2R relationship is unclear or may not exit, and the selection pressures to maintain MC2R primary sequence identity does not appear to be as strong. For example, in a recent study, on stingray MCRs (39), $m c 2 r$ and $m c 5 r$ mRNA levels were detected in the interrenal tissue of this species. However, the $\mathrm{EC}_{50}$ value of the stingray MC5R for ACTH (1-24) was in the $10^{-9} \mathrm{M}$ range, whereas the $\mathrm{EC}_{50}$ value for stingray $\mathrm{MC} 2 \mathrm{R}$ was in the $10^{-7} \mathrm{M}$ range. In this example, MC5R rather MC2R may be the "ACTH" receptor in the HPI axis of the stingray.

The diminished primary sequence conservation for MC2R orthologs is in sharp contrast to the higher degree of primary sequence conservation for stingray and human MC5R orthologs (55\%; Figure 6A). In addition, for two very distantly related bony fish MC5R orthologs (gar and fugu) the sequence identity was $73 \%$ (Figure 6B). These observations beg the question of the functional significance of the stability of MC5R orthologs during the radiation of the gnathostomes. For mammals, MC5R plays a role in exocrine gland secretion (61). However, the role of the MC5R receptor in non-mammalian vertebrates is largely unknown. Perhaps a renewed focus on the distribution of MC5 receptors in various tissues of non-mammalian vertebrates will yield some answers.

\section{CONCLUSION}

While it has been nearly 25 years since the cloning of the first MCRs $(6,11)$, and nearly 40 years since the structure/function studies on ACTH (41), there are still many aspects of the pharmacology and physiology of the melanocortin peptides and the

\section{REFERENCES}

1. Vastermark A, Schiöth HB. The early origin of melanocortin receptors, agouti-related peptide, agouti signaling peptide, and melanocortin receptor-accessory proteins, with emphasis on pufferfishes, elephant shark, lampreys, and amphioxus. Eur J Pharmacol (2011) 660:61-9. doi:10.1016/j. ejphar.2010.10.106

2. Ohno S, Wolf U, Atkins NB. Evolution from fish to mammals by gene duplication. Hereditas (1968) 59:169-87. doi:10.1111/j.1601-5223.1968.tb02169.x

3. Lundin LG. Evolution of the vertebrate genome as reflected in paralogous chromosomal regions in man and the house mouse. Genomics (1993) 16:1-19. doi:10.1006/geno.1993.1133

4. Holland PW, Garcia-Fernandez J, Williams NA, Sidow A. Gene duplications and the origins of vertebrate development. Dev Suppl (1994):125-33.

5. Gallo-Payet N, Battista M-C. Steroidogenesis - adreanl cells signal transduction. Compr Physiol (2014) 4:889-964. doi:10.1002/cphy.c130050

6. Cone RD. Studies on the physiological functions of the melanocortin system. Endocr Rev (2006) 27:736-49. doi:10.1210/er.2006-0034

7. Takahashi A, Amemiya Y, Sarashi M, Sower SA, Kawauchi H. Melanotropin and corticotropin are encoded on two distinct genes in the lamprey, the earliest evolved extant vertebrate. Biochem Biophys Res Commun (1995) 213:490-8. doi:10.1006/bbrc. 1995.2158
MCRs that have not been resolved. One of the interesting facets of this receptor family is the interaction with the MRAPs $(8,9$, $16,17)$. The presence of a mrap1 ortholog in the genome of a cartilaginous fish suggests that the mrap1 and the mrap2 paralogous genes were the result of the $2 \mathrm{R}$ genome duplication event (2). There is still a considerable amount of work to be done to clarify the physiological roles of the MRAP1 and MRAP2 in nonmammalian vertebrates, and the contact sites between MRAPs and the MCRs that can influence ligand selectivity.

When considering the functional activation of the MCRs, the paralogs $\mathrm{MC} 1 \mathrm{R}, \mathrm{MC} 3 \mathrm{R}, \mathrm{MC} 4 \mathrm{R}$, and MC5R are activated through an HFRW-binding site on these receptors that appears to be highly conserved. However, the MC2R orthologs of teleosts and tetrapods appear to utilize an additional binding site for the R/KKRR motif in gnathostome ACTH. Recent studies on cartilaginous fish MC2R orthologs suggest that a single-binding site may be all that is needed for the activation of these receptors $(39,46)$. Identifying the functional domains within the various gnathostome MC2R orthologs may clarify the ligand selectivity properties of cartilaginous fish and teleost/tetrapod MC2R orthologs.

Finally, while the role for MC2R orthologs in the HPA/HPI axis seems very clear, the role of the MC5R orthologs in the physiology of non-mammalian vertebrates is not resolved. The possibility that MC2R and MC5R may be functioning in the same cells should be considered.

\section{AUTHOR CONTRIBUTIONS}

The author confirms being the sole contributor of this work and approved it for publication.

\section{FUNDING}

This research was supported by the Long Research Fund (University of Denver).

8. Hinkle PM, Sebag JA. Structure and function of the melanocortin 2 receptor accessory protein. Mol Cell Endocrinol (2009) 300:25-31. doi:10.1016/j. mce.2008.10.041

9. Webb TR, Clark AJ. Mini-review: the melanocortin 2 receptor accessory proteins. Mol Endocrinol (2010) 24:475-84. doi:10.1210/me.2009-0283

10. Gantz I, Fong TM. The melanocortin system. Am J Physiol Endocrinol Metab (2003) 284:E468-74. doi:10.1152/ajpendo.00434.2002

11. Mountjoy KG, Robbins LS, Mortrud MT, Cone RD. The cloning of a family of genes that encode the melanocortin receptors. Science (1992) 257:1248-51. doi:10.1126/science. 1325670

12. Noon LA, Franklin JM, King PJ, Goulding NJ, Hunyady L, Clark AJ. Failed export of the adrenocorticotropin receptor from the endoplasmic reticulum in non-adrenal cells: evidence in support of a requirement for a specific adrenal accessory factor. J Endocrinol (2002) 174:17-25. doi:10.1677/ joe. 0.1740017

13. Rached M, El Mourabit H, Buronfosse A, Blondet A, Naville D, Begeot M, et al. Expression of the human melanocortin-2 receptor in different eukaryotic cells. Peptides (2005) 26:1842-7. doi:10.1016/j.peptides.2004.11.037

14. Kilianova Z, Basora N, Kilian P, Payet MD, Gallo-Payet N. Human melanocortin receptor 2 expression and functionality: effects of protein kinase A and protein kinase C on desensitization and internalization. Endocrinology (2006) 147:2325-37. doi:10.1210/en.2005-0991 
15. Roy S, Rached M, Gallo-Payet N. Differential regulation of the human adrenocorticotropin receptor [melanocortin-2 receptor (MC2R)] by human MC2R accessory protein isoforms $\alpha$ and $\beta$ in isogenic human embryonic kidney 293 cells. Mol Endocrinol (2007) 21:1656-69. doi:10.1210/ me.2007-0041

16. Metherell LA, Chapple JP, Cooray S, David A, Becker C, Ruschendorf F, et al. Mutations in MRAP, encoding a new interacting partner of the ACTH receptor, cause familial glucocorticoid deficiency type 2. Nat Genet (2005) 37:166-70. doi:10.1038/ng1501

17. Chan LF, Webb TR, Chung T-T, Meimaridou E, Cooray SN, Guasti L, et al. MRAP and MRAP2 are bidirectional regulators of the melanocortin receptor family. Proc Natl Acad Sci U S A (2009) 106:6146-51. doi:10.1073/ pnas.0809918106

18. Sebag JA, Hinkle PM. Regions of melanocortin (MC2) receptor accessory protein necessary for duel topology and MC2 receptor trafficking and signaling. J Biol Chem (2009) 284:610-8. doi:10.1074/jbc.M804413200

19. Barlock TK, Gehr DT, Dores RM. Analysis of the pharmacological properties of chicken melanocortin-2 receptor (cMC2R) and chicken melanocortin-2 accessory protein (cMRAP). Gen Comp Endocrinol (2014) 205:260-7. doi:10.1016/j.ygcen.2014.03.045

20. Agulleiro MA, Roy S, Sanchez E, Puchol S, Gallo-Payet N, Cerda-Reverter JM. Role of melanocortin receptor accessory proteins in the function of zebrafish melanocortin receptor type 2. Mol Cell Endocrinol (2010) 320:145-52. doi:10.1016/j.mce.2010.01.032

21. Liang L, Sebag JA, Eagelston L, Serasinghe MN, Veo K, Reinick C, et al. Functional expression of frog and rainbow trout melanocortin 2 receptors using heterologous MRAP1s. Gen Comp Endocrinol (2011) 174:5-14. doi:10.1016/j.ygcen.2011.07.005

22. Sebag JA, Hinkle PM. Melanocortin-2 receptor accessory protein MRAP forms antiparallel homodimers. Proc Natl Acad Sci U S A (2007) 104:20244-9. doi:10.1073/pnas.0708916105

23. Dores RM, Garcia Y. Views on the co-evolution of the melanocortin-2 receptor, MRAPs, and the hypothalamus/pituitary/adrenal-interrenal axis. Mol Cell Endocrinol (2015) 408:12-22. doi:10.1016/j.mce.2014.12.022

24. Dores RM, Liang L, Hollmann RE, Sandhu N, Vijayan MM. Identifying the activation motif in the N-terminal of rainbow trout and zebrafish melanocortin-2 receptor accessory protein 1 (MRAP1) orthologs. Gen Comp Endocrinol (2016). doi:10.1016/j.ygcen.2015.12.031

25. Boston $\mathrm{BA}$, Cone $\mathrm{RD}$. Characterization of melanocortin receptor subtypes expression in murine adipose tissue and in 3T3-L1 cell line. Endocrinology (1996) 137:2043-50. doi:10.1210/en.137.5.2043

26. Nimura M, Udagawa J, Hatta T, Hashimodo R, Otani H. Spacial and temporal patterns of expression of melanocortin type 2 and 5 receptors in the fetal mouse tissues and organs. Anat Embryol (Berl) (2006) 211:109-17. doi:10.1007/s00429-005-0066-9

27. Sebag JA, Hinkle PM. Opposite effects of the melanocortin-2(MC2) receptor accessory protein MRAP on MC2 and MC5 receptor dimerization and trafficking. J Biol Chem (2009) 284:22641-8. doi:10.1074/jbc.M804413200

28. Takeuchi S, Takahashi S. Melanocortin receptor genes in the chicken - tissue distributions. Gen Comp Endocrinol (1998) 112:210-9. doi:10.1006/gcen.1998.7167

29. Haitina T, Klovins J, Andersson J, Fredriksson R, Lagerstrom MC, Larhammar $\mathrm{D}$, et al. Cloning, tissue distribution, pharmacology and three-dimensional modeling of melanocortin receptors 4 and 5 in rainbow trout suggest close evolutionary relationship of these subtypes. Biochem J (2004) 380:475-86. doi:10.1042/bj20031934

30. Huszar D, Lynch CA, Fairchild-Huntress V, Dunmore JH, Fang Q, Berkemeier LR, et al. Targeted disruption of the melanocortin- 4 receptor results in obesity in mice. Cell (1997) 88:131-41. doi:10.1016/S0092-8674(00)81865-6

31. Sebag JA, Zhang C, Hinkle PM, Bradshaw AM, Cone RD. Developmental control of the melanocortin-4 receptor by MRAP2 proteins in zebrafish. Science (2013) 341:278-81. doi:10.1126/science.1232995

32. Asai M, Ramachandrappa S, Joachim M, Shen Y, Zhang R, Nuthalapati N, et al. Loss of function of the melanocortin 2 receptor accessory protein 2 is associated with mammalian obesity. Science (2013) 34(1):275-8. doi:10.1126/ science. 1233000

33. Kay EI, Botha R, Montgomery JM, Mountjoy KG. hMRAP $\alpha$, but not hMRAP2, enhances hMC4R constitutive activity in HEK293 cells and this is not dependent on hMRAP $\alpha$ induced changes in hMC4R complex N-linked glycosylation. PLoS One (2015) 10(10):e0140320. doi:10.1371/journal. pone. 0140320

34. Aguilleiro MA, Cortes R, Fernandez-Duran B, Navarro S, Guillot R, Meimmaridou E, et al. Melanocortin 4 receptor becomes an ACTH receptor by coexpression of melanocortin receptor accessory protein 2. Mol Endocrinol (2013) 27:1934-45. doi:10.1210/me.2013-1099

35. Meyer A, Van de Peer Y. From 2R to 3R: evidence for a fish-specific genome duplication (FSGD). Bioessays (2005) 27:937-45. doi:10.1002/bies.20293

36. Zhu M, Xiaobo Y, Choo B, Lu J, Qiao T, Qu Q, et al. A Silurian placoderm with osteichthyan-like marginal jaw bones. Nature (2013) 502:188-93. doi:10.1038/ nature12617

37. Davis P, Franquemont S, Liang L, Angleson JK, Dores RM. Review: evolution of the melanocortin-2 receptor in tetrapods: studies on Xenopus tropicalis MC2R and Anolis carolinensis MC2R. Gen Comp Endocrinol (2013) 188:75-84. doi:10.1016/j.ygcen.2013.04.007

38. Reinick CL, Liang L, Angleson JK, Dores RM. Identification of an MRAPindependent melanocortin-2 receptor: functional expression of the cartilaginous fish, Callorhinchus milii, melanocortin-2 receptor in $\mathrm{CHO}$ cells. Endocrinology (2012) 153:4757-65. doi:10.1210/en.2012-1482

39. Takahashi A, Davis P, Reinick C, Mizusawa K, Sakamoto T, Dores RM Characterization of melanocortin receptors from stingray Dasyatis akajei, an elasmobranchs. Gen Comp Endocrinol (2016). doi:10.1016/j.ygcen.2016.03.030

40. Ling MK, Hotta E, Kilanova Z, Haitina T, Ringholm A, Johansson L, et al. The melanocortin receptor subtypes in chicken have high preference to ACTH-derived peptides. Br J Pharmacol (2004) 143:626-37. doi:10.1038/ sj.bjp. 0705900

41. Schwyzer R. ACTH: a short introductory review. Ann N Y Acad Sci (1977) 297:3-26. doi:10.1111/j.1749-6632.1977.tb41843.x

42. Dores RM, Londraville RL, Prokop J, Davis P, Dewey N, Lesinski N. The evolution of melanocortin receptor: the relationship between pharmacology and physiology. J Mol Endocrinol (2014) 52:T29-42. doi:10.1530/JME-14-0050

43. Klovins J, Haitina T, Fridmanis D, Kilianova Z, Kapa K, Fredriksson R, et al. The melanocortin system in Fugu: determination of POMC/AGRP/ MCR gene repertoire and synteny, as well as pharmacology and anatomical distribution of the MCRs. Mol Biol Evol (2004) 21:563-79. doi:10.1093/ molbev/msh050

44. Ringholm A, Klovins J, Fredriksson R, Poliakova N, Larson ET, Kukkonen JP, et al. Presence of melanocortin (MC4) receptor in spiny dogfish suggests an ancient vertebrate origin of central melanocortin system. Eur J Biochem (2003) 270:213-21. doi:10.1046/j.1432-1033.2003.03371.x

45. Klovins J, Haitina T, Ringholm A, Lowgren M, Fridmanis D, Slaidina M, et al. Cloning of two melanocortin (MC) receptors in spiny dogfish. Eur J Biochem (2004) 271:4320-31. doi:10.1111/j.1432-1033.2004.04374.x

46. Reinick CL, Liang L, Angleson JK, Dores RM. Functional expression of Squalus acanthias melanocortin 5 receptor in $\mathrm{CHO}$ cells, ligand selectivity and interaction with MRAP. Eur J Pharmacol (2012) 680:1-7. doi:10.1016/j. ejphar.2012.01.021

47. Pogozheva ID, Chai B-X, Lomize AL, Fong TM, Weinberg DH, Nargund RP, et al. Interactions of human melanocortin 4 receptors with nonpeptide and peptide agonists. Biochemistry (2005) 44:11329-41. doi:10.1021/bi0501840

48. Fridmanis D, Petrovska R, Kalnina I, Slaidina M, Peculis R, Schiöth HB, et al. Identification of domains responsible for specific membrane transport and ligand specificity of the ACTH receptor (MC2R). Mol Cell Endocrinol (2010) 321:175-83. doi:10.1016/j.mce.2010.02.032

49. Hinkle PM, Serasinghe MN, Jakebowski A, Sebag JE, Wilson KA, HaskellLuevano C. Use of chimeric melanocortin-2 and -4 receptors to identity regions responsible for ligand specificity and dependence on melanocortin 2 accessory protein. Eur J Pharmacol (2011) 660:94-102. doi:10.1016/j. ejphar.2010.10.113

50. Dores RM, Liang L, Davis P, Thomas AL, Petko B. Melanocortin receptors: evolution of ligand selectivity for melanocortin peptides. J Mol Endocrinol (2016) 56:T1-16. doi:10.1530/JME-15-0292

51. Malik S, Dolan TM, Maben J, Hinkle PM. ACTH responses require actions of the melanocortin-2 receptor accessory protein on the extracellular surface of the plasma membrane. J Biol Chem (2015) 290:27972-85. doi:10.1074/jbc. M115.668491

52. Schiöth HB, Haitina T, Ling MK, Ringholm A, Fredricksson R, Cerda-Reverter $\mathrm{JM}$, et al. Evolutionary conservation of the structural, pharmacological, and 
genomic characteristics of the melanocortin receptor subtypes. Peptides (2005) 26:1886-900. doi:10.1016/j.peptides.2004.11.034

53. Schiöth HB, Raudsepp T, Ringholm A, Fredriksson R, Takeuchi S, Larhammar $D$, et al. Remarkable synteny conservation of melanocortin receptors in chicken, human, and other vertebrates. Genomics (2003) 81:504-9. doi:10.1016/S0888-7543(03)00028-4

54. Baron A, Veo K, Angleson J, Dores RM. Modeling the evolution of the MC2R and MC5R genes: studies on the cartilaginous fish, Heterondotus francisci. Gen Comp Endocrinol (2009) 161:13-9. doi:10.1016/j.ygcen.2008.11.026

55. Dores RM. Observations on the evolution of the melanocortin receptor gene family: distinctive features of the melanocortin-2 receptor. Front Endocrinol (2013) 10(7):28. doi:10.3389/fnins.201300028

56. Rasmussen A-S, Arnason U. Molecular studies suggest that cartilaginous fishes have a terminal position in the piscine tree. Proc Natl Acad Sci U S A (1999) 96:2177-82. doi:10.1073/pnas.96.5.2177

57. Munck A, Guyre PM, Holbrook NJ. Physiological functions of glucocorticoids in stress and their relation to pharmacological actions. Endocr Rev (1984) 5:25-44. doi:10.1210/edrv-5-1-25

58. Smith SM, Valle WW. The role of the hypothalamus-pituitary-adrenal axis in neuroendocrine responses to stress. Dialogues Clin Neurosci (2006) 8:383-95.
59. Flik G, Klaven PHM, Van den Burg EH, Metz JR, Huising MO. CRF and stress in fish. Gen Comp Endocrinol (2006) 146:36-44. doi:10.1016/j. ygcen.2005.11.005

60. Crespi EJ, Williams TD, Jessop TS, Delehanty B. Life history and the ecology of stress: how do glucocorticoid hormones influence life-history variation in animals? Funct Ecol (2013) 27:93-116. doi:10.1111/1365-2435.12009

61. Zhang L, Li WH, Anthonavage M, Pappas A, Rossetti D, Cavender D, et al. Melanocortin-5 receptor and sebogenesis. Eur J Pharmacol (2011) 660:202-6. doi:10.1016/j.ejphar.2010.10.100

Conflict of Interest Statement: The authors declare that the research was conducted in the absence of any commercial or financial relationships that could be construed as a potential conflict of interest.

Copyright $\odot 2016$ Dores. This is an open-access article distributed under the terms of the Creative Commons Attribution License (CC BY). The use, distribution or reproduction in other forums is permitted, provided the original author(s) or licensor are credited and that the original publication in this journal is cited, in accordance with accepted academic practice. No use, distribution or reproduction is permitted which does not comply with these terms. 